\title{
Multicomponent complex formation between vinpocetine, cyclodextrins, tartaric acid and water-soluble polymers monitored by NMR and solubility studies
}

\author{
Laura Ribeiro $^{\text {a }}$, Rui A. Carvalho ${ }^{\mathrm{b}}$, Domingos C. Ferreira ${ }^{\mathrm{c}}$, Francisco J.B. Veiga ${ }^{\mathrm{a}, *}$ \\ ${ }^{a}$ Laboratory of Pharmaceutical Technology, Faculty of Pharmacy, University of Coimbra, 3000-295 Coimbra, Portugal \\ ${ }^{\mathrm{b}}$ Department of Biochemistry, Faculty of Sciences and Technology, University of Coimbra, Coimbra, Portugal \\ ${ }^{\mathrm{c}}$ Laboratory of Pharmaceutical Technology, Faculty of Pharmacy, University of Porto, Porto, Portugal
}

Received 25 February 2004; received in revised form 25 May 2004; accepted 14 September 2004

Available online 14 November 2004

\begin{abstract}
This work deals with multicomponent complex formation of vinpocetine (VP) with $\beta$-cyclodextrin ( $\beta C D$ ), sulfobutyl ether $\beta$-cyclodextrin $(\mathrm{SBE} \beta \mathrm{CD})$ and tartaric acid (TA), in the presence or absence of water-soluble polymers, in aqueous solution. Complexation was monitored by phase-solubility and proton nuclear magnetic resonance $\left({ }^{1} \mathrm{H}\right.$ NMR) studies. TA demonstrated a synergistic effect on VP solubility, and in the complexation efficiency of $\beta C D$ and SBE $\beta C D$. Additionally, water-soluble polymers increased even more the complexation efficiency of the CDs that was reflected by a 2.1-2.5 increase on $K_{\mathrm{C}}$ values for VP-CD-TA-polymer multicomponent complexes. SBE $3 C D$ was more effective in VP solubilization, as $K_{\mathrm{C}}$ values of VP-SBE $\beta C D-T A$ multicomponent complexes were notably higher than in corresponding $\beta C D$ complexes. The large chemical shift displacements from protons located in the interior of the hydrophobic CD cavities (i.e., H-3 and H-5) coupled with significant chemical shift displacements of VP aromatic protons suggested that this moiety was included in the cavity of both $\beta C D$ and SBE$\beta C D$. Two-dimensional rotating frame nuclear Overhauser effect spectroscopy (ROESY) experiments were carried out in order to obtain information about the multicomponent complex geometry in solution. Inspection of ROESY spectra allowed the establishment of spatial proximities between all aromatic protons of VP and the internal protons of the CDs, confirming that the aromatic moiety of VP is included in CD cavities being deeply inserted in SBEßCD multicomponent complexes, since additional interactions with the sulfobutyl side chains were evidenced.
\end{abstract}

(C) 2004 Elsevier B.V. All rights reserved.

Keywords: Vinpocetine; Cyclodextrins; Water-soluble polymers; Phase-solubility studies; ${ }^{1} \mathrm{H}$ NMR; Multicomponent complexes

\section{Introduction}

Cyclodextrins (CDs) are naturally available watersoluble cyclic oligosaccharides composed of $\alpha-1,4$-linked Dglucopyranose units. The most commonly used forms of these ring-shaped molecules are $\alpha-, \beta$-, and $\gamma$-CDs formed by six, seven and eight glucose units, respectively (Szejtli, 1988). CDs are toroidal molecules with a truncated cone structure where the secondary hydroxyl groups are located on the wider

\footnotetext{
* Corresponding author. Tel.: +351 2398 37850; fax: +351 239837731 . E-mail address: fveiga@ ci.uc.pt (F.J.B. Veiga).
}

side of the ring, while the primary hydroxyl groups are positioned on the opposite, narrower side of the torus. The $-\mathrm{CH}$ groups carrying the $\mathrm{H}-1, \mathrm{H}-2$ and $\mathrm{H}-4$ protons are located on the exterior of the molecule and the hydroxyl groups are oriented to the cone exterior, making the external faces of CDs hydrophilic. The interior of the torus is lined by two rings of $-\mathrm{CH}$ groups $(\mathrm{H}-3$ and $\mathrm{H}-5)$ and by a ring of glycosidic "ether oxygens" (O-4), with H-6 located near the cavity (Uekama and Otagiri, 1987). This low polarity central void is able to encapsulate either partially or entirely a great variety of guest molecules of suitable size and shape resulting in a stable association without formation of covalent bonds, 


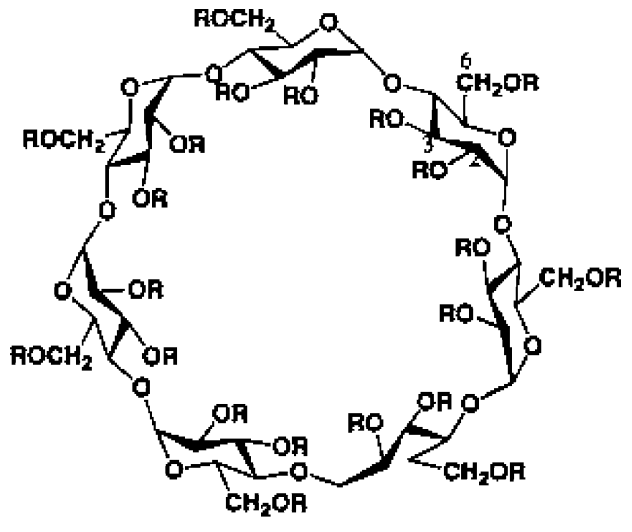

(a) $\mathrm{R}=\mathrm{H}$ or $\left[-\mathrm{CH}_{2}-\mathrm{CH}_{2}-\mathrm{CH}_{2}-\mathrm{CH}_{2}-\mathrm{SO}_{3}{ }^{-} \mathrm{Na}^{+}\right]_{\mathrm{n}}$ a $\quad$ b $\quad$ c $\quad$ d

(b) $\mathbf{R}=\mathbf{H}$

Where

$\mathbf{n}=$ average degree of substitution (7)

Fig. 1. Structure of (a) SBE $\beta C D$ and (b) $\beta C D$.

being the resultant entity known as host-guest complex or inclusion complex (Saenger, 1980). When compared to host and guest separately, these inclusion complexes often display very different properties such as altered solubility, reduced volatitility, reduced or enhanced stability, modified chemical reactivity and altered bioavailability.

Among the above mentioned CDs, $\beta C D$, with an inner cavity diameter of $6.0-6.5 \AA$ and a depth of $7.9 \AA$, is the most widely used. Its internal cavity has an excellent ability to incorporate hydrophobic aromatic guests in aqueous solution, provided that the sizes of the host internal cavity and the entering portion of a guest molecule are suitable for complexation (Saenger, 1980). However, its anomalous low aqueous solubility is a serious handicap in its wider utilization (Szejtli, 1988). To overcome those difficulties, chemical modifications of the $\mathrm{CD}$ torus by substitution at the hydroxyl groups, at positions 2,3 and 6 of the $\alpha$-Dglucose have been made to enhance and expand the functionalities of CDs, leading to derivatives that provide better solubility. One of the most prominent groups of modified CDs, as far as pharmaceutical applications are concerned, are the sulfobutyl-substituted CDs (Fig. 1), among which is the (sulfobutylether) ${ }_{7 \mathrm{M}}-\beta$-cyclodextrin (SBE $\beta C D$ ). SBE $\beta C D$ is a polyanionic $\mathrm{CD}$ derivative, with an average degree of substitution of seven and a much greater solubility in water than the parent $C D(\beta C D)$. The inclusion ability of SBE $\beta C D$ is generally greater than that of $\beta C D$ due to the hydrophobic butyl side arms that extend the hydrophobic cavity of the $\mathrm{CD}$ (Zia et al., 2001).

Frequently, the complexation efficiency of CDs is rather low and consequently a significant amount of CDs is frequently needed to solubilize small amounts of a waterinsoluble drug. However, drug solubility in the presence of
CD can be dramatically improved by addition of a suitable third component such as $\alpha$-hydroxy-acids, and watersoluble polymers followed by heating the complexation media (Loftsson et al., 1999; Chiesi et al., 1999).

CD inclusion complexes formed by molecular encapsulation of guest compounds in the cavities of macrocyclic hosts can yield non-covalent multicomponent associations with suitable counter ions of guest molecules. Such multicomponent associations are of current interest in the field of supramolecular systems and are of scientific interest and technological relevance for their physical, chemical and biological properties (Selva et al., 1998). In the field of pharmaceutical preparations, multicomponent associations of drug-CD inclusion complexes can dramatically enhance the solubility in water of sparingly soluble drugs (Chiesi et al., 1999).

Previously, we have reported the preparation and physicochemical characterization of vinpocetine (VP) multicomponent complexes with $\beta C D$, SBE $\beta C D$, tartaric acid (TA) and the water-soluble polymers hydroxypropylmethylcellulose (HPMC) and polyvinylpyrrolidone K30 (PVP), in solidstate, by scanning electron microscopy, differential scanning calorimetry, X-ray diffractometry and Fourier-transform infrared spectroscopy (Ribeiro et al., 2003a,b). However, these techniques can hardly suggest if guest molecules form a complex or not and cannot provide a clear answer about the type of complex formed (inclusion or adsorption) or the structural conformation of the molecules involved (Djedaini and Perly, 1991; Veiga et al., 2001). This information can only be provided by high resolution nuclear magnetic resonance spectroscopy (NMR) since this technique allows a clear distinction between inclusion and other possible external interaction processes by observing guest and host molecules simultaneously and is capable to differentiate the part of the guest molecule involved in the interaction with the $\mathrm{CD}$ cavity (Fernandes et al., 2003). Monitoring changes in the ${ }^{1} \mathrm{H}$ chemical shifts as the composition of theses complexes is varied can elucidate the stoichiometry of inclusion complexes and the dynamics of their formation. Thus, chemical shift changes in the ${ }^{1} \mathrm{H}$ spectra have been used to monitor the complex formation process, since if a guest is incorporated into the $\mathrm{CD}$ cavity, the hydrogen atoms located in the interior of the cavity (H-3 and H-5) will be considerably shielded by the guest molecule, causing a significant upfield shift, whereas the hydrogen atoms on the outer surface (H-1, H-2, H-4 and H-6) will either be unaffected or experience a marginal shift. ${ }^{1} \mathrm{H}$ NMR can thus provide information about structure and hydrogen bonding in CDs; whereas, more detailed information about their conformations is available from a variety of bidimensional NMR experiments, including NOESY and rotating frame nuclear Overhauser effect spectroscopy (ROESY) (Szejtli, 1988; Schneider et al., 1998).

In this work, taking into account that the molecular structure of VP is characterized by the presence of an aromatic moiety that is potentially able to interact with the CD cavity (Fig. 2), we have employed phase-solubility studies, as a previous screening of the complex formation between VP, 


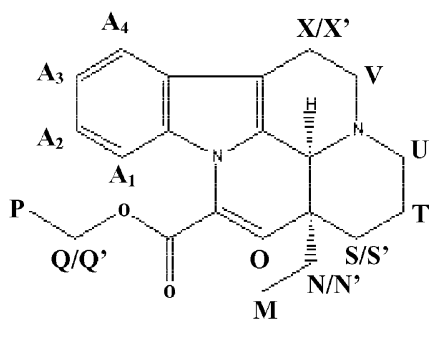

Fig. 2. Structure of VP.

$\beta C D, S B E \beta C D, T A, P V P$ and HPMC in order to evaluate the solubilizing power of CDs, in association with an hydroxyacid and water-soluble polymers, towards VP, and to determine the apparent stability constants and stoichiometry of the complexes. A series of ${ }^{1} \mathrm{H}$ NMR experiments were then undertaken to prove the real inclusion of VP in VP-CD multicomponent complexes, to confirm the stoichiometry of the putative inclusion complexes and a reliable structure of those.

\section{Materials and methods}

\subsection{Materials}

Hydroxypropylmethylcellulose 4000 cps (HPMC), polyvinylpyrrolidone K30 (PVP), and tartaric acid (TA) were purchased from Sigma Chemical Co. (St. Louis, USA). Vinpocetine (VP) was purchased from Covex (Madrid, Spain). $\beta$-Cyclodextrin $\left(\beta C D\right.$; Kleptose $\left.{ }^{\circledR} ; \mathrm{MW} 1135\right)$ and (sulfobutylether) ${ }_{7 \mathrm{M}}-\beta$-cyclodextrin (SBE $\beta \mathrm{CD} ; \mathrm{Captisol}^{\mathrm{TM}}$; TDS 6.8; MW 2160) were kindly donated by Roquette (Lestrem, France) and Cydex (Kansas City, USA). The latter was dried at $40{ }^{\circ} \mathrm{C}$ for $12 \mathrm{~h}$ before use. Deuterium oxide $\left(\mathrm{D}_{2} \mathrm{O} ; 99.90 \%\right)$ was purchased from SDS (Peypin, France). All other chemicals were of analytical reagent grade, and deionized water was used throughout the study.

\subsection{Phase-solubility studies}

Solubility studies were carried out in TA $16.6 \mathrm{mM}$ solutions at room temperature $\left(22 \pm 1^{\circ} \mathrm{C}\right)$ according to the method of Higuchi and Connors (Higuchi and Connors, 1965). Excess amounts of VP were weighted into glass flasks to which were added $10 \mathrm{ml}$ of $16.6 \mathrm{mM}$ solutions containing increasing amounts of CDs $(0.001-0.025 \mathrm{M})$ with or without a fixed polymer concentration of $0.10 \%(\mathrm{w} / \mathrm{v})$ for HPMC and $0.25 \%(\mathrm{w} / \mathrm{v})$ for PVP. For systems without polymers, glass containers were sealed and mechanically stirred until reaching equilibrium (about $72 \mathrm{~h}$ ). In the case of systems with polymers, glass containers were sealed and heated in an autoclave at $120^{\circ} \mathrm{C}$ for $20 \mathrm{~min}$ and then allowed to equilibrate for $72 \mathrm{~h}$. The polymer and TA concentrations used were selected on the basis of preliminary studies carried out between VP and polymers or VP and TA, since no further improvement in the solubility values of VP was achieved by increasing polymer concentrations and no significant degradation of $\mathrm{VP}$ in acidic medium was found after autoclavation at $120^{\circ} \mathrm{C}$ for $20 \mathrm{~min}$. All suspensions were filtered through a 0.45 $\mu \mathrm{m}$ membrane filter (Millipore) and VP concentrations analyzed spectrophotometrically (UV-1603, Shimadzu, Japan) at $316 \mathrm{~nm}$. Each experiment was repeated at least three times and the results reported are the mean values. The apparent stability constants $\left(K_{\mathrm{C}}\right)$, assuming that a 1:1 (VP:CD) complex was initially formed, were calculated from the straight line of the phase-solubility diagrams according to the equation of Higuchi and Connors.

\section{3. ${ }^{1}$ H NMR studies}

One-dimensional ${ }^{1} \mathrm{H}$ NMR spectra were recorded at $25^{\circ} \mathrm{C}$ on a Varian $500 \mathrm{MHz}$ spectrometer using a $5 \mathrm{~mm}$ NMR probe and a simple pulse-acquire sequence with solvent presaturation. Acquisition parameters consisted of $16 \mathrm{~K}$ points covering a sweep width of $5300 \mathrm{~Hz}$, a pulse width of $19 \mu \mathrm{s}$ and a total repetition time of $13 \mathrm{~s}$. Digital zero filling to $64 \mathrm{~K}$ and a $0.5 \mathrm{~Hz}$ exponential were applied before Fourier transformation. The resonance at $4.700 \mathrm{ppm}$ due to residual solvent (HOD) was used as the internal reference. Samples were prepared by dissolving an appropriate amount of the solid complexes in $\mathrm{D}_{2} \mathrm{O}$ to achieve a VP concentration of $6.8 \mathrm{mM}$, directly on 5-mm RMN tubes ( $0.6 \mathrm{ml}$ total volume). The solid multicomponent complexes were prepared by the lyophilization method as previously described (Ribeiro et al., 2003a). Reference samples containing pure VP and CDs at $6.8 \mathrm{mM}$ were also prepared in the same acidic environment as the complexes (TA $16.6 \mathrm{mM}$ ). ${ }^{1} \mathrm{H}$ NMR chemical shifts $(\Delta \delta)$ caused upon complexation were measured to confirm the inclusion of VP in acidic medium and calculated according to the formula: $\Delta \delta=\delta$ (complex) $-\delta$ (free) .

The continuous variation method (Job's plot) was adopted to assess the stoichiometry of the complexes. TA solutions of $16.6 \mathrm{mM}$ were prepared, with or without $0.1 \%$ HPMC (w/v) or $0.25 \%(\mathrm{w} / \mathrm{v})$ in $\mathrm{D}_{2} \mathrm{O}$, and subsequently used to obtain $6.8 \mathrm{mM}$ stock solutions of VP and both CDs. A series of solutions were prepared by mixing variable volumes of both stock solutions in varying proportions so that a complete range of mole ratios was sampled $(0>[\mathrm{VP}] /[\mathrm{VP}]+[\mathrm{CD}]>1)$, keeping total concentration constant $([\mathrm{VP}]+[\mathrm{CD}]=6.8 \mathrm{mM})$. Chemical shift differences $(\Delta \delta) \times[\mathrm{VP}]$ (or $[\beta C D]$ ) were plotted as a function of mole ratio ( $r$ ) (Mitra et al., 1998).

\subsection{COSY experiments}

Standard absorptive two-dimensional ${ }^{1} \mathrm{H}-{ }^{1} \mathrm{H}$ chemical shift correlation spectra (COSY) were acquired in the same spectrometer to allow the chemical shift assignment of VP in TA solution. Each spectrum consisted of a matrix of $2 \mathrm{~K}$ (F2) by $0.5 \mathrm{~K}$ (F1) covering a sweep width of $5000 \mathrm{~Hz}$. Before Fourier transformation, the matrix was zero filled to $4 \mathrm{~K}$ by $2 \mathrm{~K}$ and standard sinebell apodization functions were applied in both dimensions. 


\subsection{ROESY experiments}

The average extent of penetration and the direction of inclusion in the host cavity were determined by twodimensional phase sensitive nuclear Overhauser effect spectroscopy by the detection of intermolecular nuclear Overhauser effects (NOEs) between VP and CDs. ROESY spectra were acquired in the phase sensitive mode using the same spectrometer. Each spectrum consisted of a matrix of $2 \mathrm{~K}(\mathrm{~F} 2)$ by $1 \mathrm{~K}$ (F1) covering a sweep width of $5000 \mathrm{~Hz}$. Spectra were obtained with the samples prepared from lyophilized multicomponent complexes used for ${ }^{1} \mathrm{H}$ NMR studies, using spinlock mixing periods of $500 \mathrm{~ms}$. Before Fourier transformation, the matrix was zero filled to $4 \mathrm{~K}$ by $4 \mathrm{~K}$ and sinebell apodization functions were applied in both dimensions to enhance spectral resolution. The ROESY spectra were normalized and plotted with similar intensity contour levels for all systems studied.

\section{Results and discussion}

\subsection{Phase-solubility studies}

Since VP is a poorly water-soluble base-type drug, multicomponent complexation with TA was attempted to intensify solubilization by CDs. Phase-solubility studies of VP in multicomponent systems with CDs and TA, with and without polymers, were performed to obtain information about the drug solubilization mechanism. The phase-solubility profiles of VP in $16.6 \mathrm{mM}$ TA-CD solutions, in the presence or absence of HPMC $0.10 \%(w / v)$ and PVP $0.25 \%$ (w/v) are shown in Fig. 3.

VP solubility increased linearly as a function of both $\beta C D$ and SBE $\beta C D$ concentrations, giving $A_{L}$-type phase- solubility diagrams in the $\mathrm{CD}$ concentration range studied (Higuchi and Connors, 1965) and indicating the formation of 1:1 stoichiometry VP-CD complexes in $16.6 \mathrm{mM}$ TA solution, in the presence or absence of HPMC and PVP. The increment of VP solubility seems to be related to the inclusion ability of the CD molecules in TA solution. As the slopes of these solubility diagrams were all less than 1 , it was possible to calculate the apparent stability constants $\left(K_{\mathrm{C}}\right)$ of the multicomponent complexes. The estimated $K_{\mathrm{C}}$ and VP solubility values achieved in the multicomponent systems are collected in Table 1. As it can be observed, the addition of the water-soluble polymers to the complexation media resulted in an increase on the diagram slopes that was reflected on enhanced VP solubility. Thus, VP solubility in the presence of CDs, TA and polymers resulted in a synergistic effect and in an increase on CD complexation efficiency. The binding potential and the solubilization effect of SBE $\beta C D$ were higher than that of $\beta C D$. This effect may be due to the butyl micellar arms of SBE $\beta C D$ that extend the depth of the hydrophobic cavity of the CD (Zia et al., 2001). Therefore, $K_{\mathrm{C}}$ values of VP-SBE $\beta C D-T A$ multicomponent complexes were greater than those obtained with VP- $\beta C D-T A$ multicomponent complexes, since the complexation with the SBE $\beta C D$ may involve the CD cavity and the hydrophobic sulfobutyl ether substituents.

Similar solubility results were previously reported by us (Ribeiro et al., 2003a,b) concerning the solubility of VP merely in the presence of CDs and water-soluble polymers, where a VP synergistic solubility effect was also observed in the presence both PVP and HPMC, with a superior solubilization and complexation effect being attributed to SBEßCD. The major difference between these two studies is the presence of TA. TA is an $\alpha$-hydroxy-acid commonly used as cocomplexing agent with CDs to promote complex formation of basic type drugs (Redenti et al., 2000). The mechanism



Fig. 3. Phase-solubility profiles of VP, in $16.6 \mathrm{mM}$ TA solution, as a function of $\beta C D$ and SBE $\beta C D$, with or without PVP and HPMC. Each point represents the mean of three determinations. 
Table 1

Values of apparent stability constant $\left(K_{\mathrm{C}} \pm\right.$ standard deviation) and drug solubility in VP complexes $(n=3)$

\begin{tabular}{|c|c|c|c|c|c|}
\hline & $S_{1}{ }^{\mathrm{a}}$ & $S_{2}{ }^{b}$ & $S_{2} / S_{0}{ }^{\mathrm{c}}$ & $D_{2} / D_{1}^{\mathrm{d}}$ & $K_{\mathrm{C}}\left(\mathrm{M}^{-1}\right)$ \\
\hline $\mathrm{VP}-\beta C \mathrm{D}^{\mathrm{e}}$ & $0.51 \times 10^{-2}$ & $1.17 \times 10^{-2}$ & 2.3 & - & $75 \pm 3$ \\
\hline $\mathrm{VP}-\beta C D-P V P^{\mathrm{e}}$ & $0.89 \times 10^{-2}$ & $2.24 \times 10^{-2}$ & 4.4 & 2.1 & $142 \pm 4$ \\
\hline 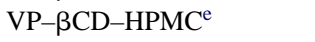 & $0.72 \times 10^{-2}$ & $3.23 \times 10^{-2}$ & 6.3 & 3.5 & $242 \pm 7$ \\
\hline VP- $\beta C D-T A$ & 5.80 & 7.59 & 1490 & 183.1 & $15 \pm 3$ \\
\hline VP- $\beta C D-T A-P V P$ & 6.06 & 9.44 & 1850 & & $37 \pm 4$ \\
\hline VP- $\beta C D-T A-H P M C$ & 5.96 & 8.41 & 1650 & 343.4 & $23 \pm 4$ \\
\hline VP-SBE $\beta C D^{\mathrm{e}}$ & $0.51 \times 10^{-2}$ & 0.14 & 27.5 & - & $340 \pm 8$ \\
\hline VP-SBEßCD-PVP & $0.89 \times 10^{-2}$ & 0.21 & 41.2 & 1.5 & $490 \pm 12$ \\
\hline VP-SBE $\beta C D-H P M C C^{\mathrm{e}}$ & $0.72 \times 10^{-2}$ & 0.16 & 31.4 & 1.4 & $390 \pm 8$ \\
\hline VP-SBE $\beta C D-T A$ & 5.80 & 10.62 & 2080 & 109.0 & $73 \pm 5$ \\
\hline VP-SBEßCD-TA-PVP & 6.06 & 12.46 & 2440 & 144.3 & $155 \pm 12$ \\
\hline VP-SBEßCD-TA-HPMC & 5.96 & 11.83 & 2320 & 136.0 & $129 \pm 12$ \\
\hline
\end{tabular}

${ }^{a}$ VP solubility $(\mathrm{mg} / \mathrm{ml})$ in water, PVP $0.25 \%(\mathrm{w} / \mathrm{v})$, HPMC $0.10 \%(\mathrm{w} / \mathrm{v})$, TA $16.6 \mathrm{mM}$ solution or in their combinations.

b VP solubility $(\mathrm{mg} / \mathrm{ml})$ in CD solutions $(15 \mathrm{mM} \beta \mathrm{CD}$ or $60 \mathrm{mM}$ SBE $\beta C D$ in the absence of TA $16.6 \mathrm{mM}$ or $25 \mathrm{mM}$ for either $\beta C D$ or SBE$\beta C D$ in the presence of TA $16.6 \mathrm{mM})$ with and without PVP $0.25 \%(\mathrm{w} / \mathrm{v})$ or HPMC $0.10 \%(\mathrm{w} / \mathrm{v})$.

c Ratio between VP solubility achieved in the complexes and VP intrinsic solubility in water $\left(S_{0}\right)$.

d $D_{2} / D_{1}$ is the ratio between the slopes of the phase-solubility diagrams achieved in VP-CD-TA multicomponent systems and in the corresponding binary ones.

e Ribeiro et al. (2003a).

by which TA seems to enhance the solubilization and complexation of these drugs has been related to its ability to interact with CDs by forming hydrogen bonds with their numerous hydroxyl groups (Fenyvesi et al., 1999). It is evident from all examined systems that multicomponent complexes formed between VP, CDs and TA were clearly more effective in enhancing VP solubility than the ternary complexes VP-CD-polymers. In fact, VP solubilization efficiency was improved nearly 4-41 times in VP-CD-polymers complexes and 1650-2440 times in VP-CD-TA-polymer complexes, in comparison with VP intrinsic solubility $\left(S_{0} \approx 5 \mu \mathrm{g} / \mathrm{ml}\right)$. However, in all cases, a decrease in drug-CD interaction was also experimented, as indicated by the decrease in $K_{\mathrm{C}}$ values (see Table 1). Such an effect was explained on the basis of the higher initial drug solubility due to an increased ionization of VP in the presence of TA with consequent less affinity to the apolar cavity (Mura et al., 2001). Although CD complexes of un-ionized drugs are usually of stronger stability than those of their anionic counterparts, the achieved total solubility (free ionized drug + un-ionized drug) usually increases (Redenti et al., 2000). Therefore, when TA was added to the complexation media, a greater overall VP solubility was achieved by using a combined approach of CD complexation and drug ionization. Indeed, CDs and TA had a synergistic effect on VP solubility, since a greater extent on the solubilization effect, than that expected by the addition of CD and TA separately, was displayed when used together. But even more surprising was the observed effect of HPMC and PVP on VP-CD-TA systems. The simultaneous presence of the polymers and TA on the complexation media, both known to enhance separately the complexation efficiency of CDs (Loftsson et al., 1999; Redenti et al., 2000), had a positive consequence on VP solubility and CD complexation. Their relative solubilizing efficiencies $\left(D_{2} / D_{1}\right)$ were 109-343-fold higher than that of binary complexes $\mathrm{VP}-\mathrm{CD}$, and $K_{\mathrm{C}}$ values increased 2.1-2.5 times on for VP-CD-TA-polymer multicomponent complexes, in comparison with VP-CD-TA complexes. Thus, even in acidic medium, the water-soluble polymers had an important role in the improvement of complexation efficiency of CDs towards VP, allowing better solubility results to be achieved with a reduction in the amount of $\mathrm{CD}$ required to dissolve VP.

\section{2. ${ }^{1}$ H NMR studies}

As the increased solubility of a drug in the presence of CDs observed in phase-solubility diagrams cannot be considered as a definitive proof for the formation of inclusion complexes, we performed NMR studies. NMR techniques have been widely used to investigate supramolecular assemblies in solution, their stoichiometries and structure of the resulting complexes, especially the orientation of the guest molecule in the CD cavity (Djedaini and Perly, 1991). It is well-known that the chemical shift $(\delta)$ of a given nucleus depends on its shielding constant and in turn is sensitive to medium effects. Therefore, changes in $\delta$ ( $\mathrm{ppm}$ ) values of the host and guest nuclei can provide a measure of the degree of complex formation since significant changes in the microenvironment are known to occur between the free and bound states (Wilson and Verral, 1998). As the chemical environment of some protons changes upon complexation, there is a consequent variation in the chemical shifts $(\Delta \delta)$ of ${ }^{1} \mathrm{H}$ NMR resonances (shielding or deshielding effects). NMR spectroscopy provides the most direct evidence for true inclusion complex formation since $\mathrm{H}-3$ and $\mathrm{H}-5$ hydrogens of the host, that point toward the interior of the CD cavity, are remarkably shielded, being the shift of their resonances due to magnetic anisotropic effects exerted by the guest. The guest resonances are also affected by the inclusion process, being the chemical shift of the anisotropically shielded 
Table 2

${ }^{1} \mathrm{H}$ Chemical shifts corresponding to $\beta C D$ in free and complexed state

\begin{tabular}{|c|c|c|c|c|c|c|c|}
\hline \multirow[t]{2}{*}{$\beta \mathrm{CD}$ protons } & \multicolumn{3}{|c|}{ VP- $\beta C D-T A$} & \multicolumn{2}{|c|}{ VP- $\beta C D-T A-P V P$} & \multicolumn{2}{|c|}{ VP- $\beta C D-T A-H P M C$} \\
\hline & $\delta_{(\text {free })}$ & $\delta_{\text {(complex) }}$ & $\Delta \delta^{\mathrm{a}}$ & $\delta_{\text {(complex) }}$ & $\Delta \delta^{\mathrm{a}}$ & $\delta_{\text {(complex) }}$ & $\Delta \delta^{\mathrm{a}}$ \\
\hline $\mathrm{H}-1$ & 4.999 & 4.995 & -0.004 & 4.995 & -0.004 & 4.990 & -0.009 \\
\hline $\mathrm{H}-2$ & 3.578 & 3.586 & +0.008 & 3.588 & +0.010 & 3.582 & +0.004 \\
\hline $\mathrm{H}-3$ & 3.892 & 3.844 & -0.048 & 3.839 & -0.053 & 3.835 & -0.057 \\
\hline $\mathrm{H}-4$ & 3.513 & 3.505 & -0.008 & 3.505 & -0.008 & 3.500 & -0.013 \\
\hline H-5 & 3.782 & 3.774 & -0.008 & 3.773 & -0.009 & 3.768 & -0.014 \\
\hline H-6 & 3.806 & 3.806 & 0.000 & 3.807 & +0.001 & 3.809 & +0.003 \\
\hline
\end{tabular}

${ }^{\text {a }} \Delta \delta=\delta_{(\text {complex })}-\delta_{\text {(free) }}$.

atoms modified in the NMR spectra (Ganza-Gonzalez et al., 1994).

\subsubsection{VP- $\beta C D-T A$ multicomponent complexes}

Due to fast exchange, separate sets of signals belonging to the free and complexed forms were not detected in the ${ }^{1} \mathrm{H}$ NMR spectra. The insertion of VP into $\beta C D$ cavity was clearly demonstrated by changes in the ${ }^{1} \mathrm{H}$ chemical shift values of VP and $\beta C D$ protons in all VP- $\beta C D-T A$ multicomponent complexes. Table 2 reports the chemical shift of $\beta C D$ protons in the native and complexed forms and Fig. 4 the ${ }^{1} \mathrm{H}$ spectra of VP- $\beta C D-T A$ multicomponent complexes. In the presence of VP, both $\mathrm{H}-3$ and $\mathrm{H}-5$ inner protons of $\beta C D$ undergo a consistent upfield shift, which demonstrated a clear involvement of these hydrogen atoms in host-guest interactions. As this upfield displacement has been essentially attributed to the anisotropic effect caused by the inclusion of groups rich in $\pi$-electrons of the guest molecules into the hydrophobic cavity of $\beta C D$, this observable fact was taken as an evidence of complex formation (Djedaini and Perly, 1991), giving strong indications of the insertion of the aromatic ring of VP into $\beta C D$ cavity. Furthermore, because of higher shielding effect on $\mathrm{H}-3$ proton $(-0.048$ to -0.0057$)$ with respect to H-5 ( -0.008 to -0.014$)$ it could be hypothesized that VP penetrates into the $\beta C D$ cavity from the more accessible wider side (secondary hydroxyl rim). Since all the

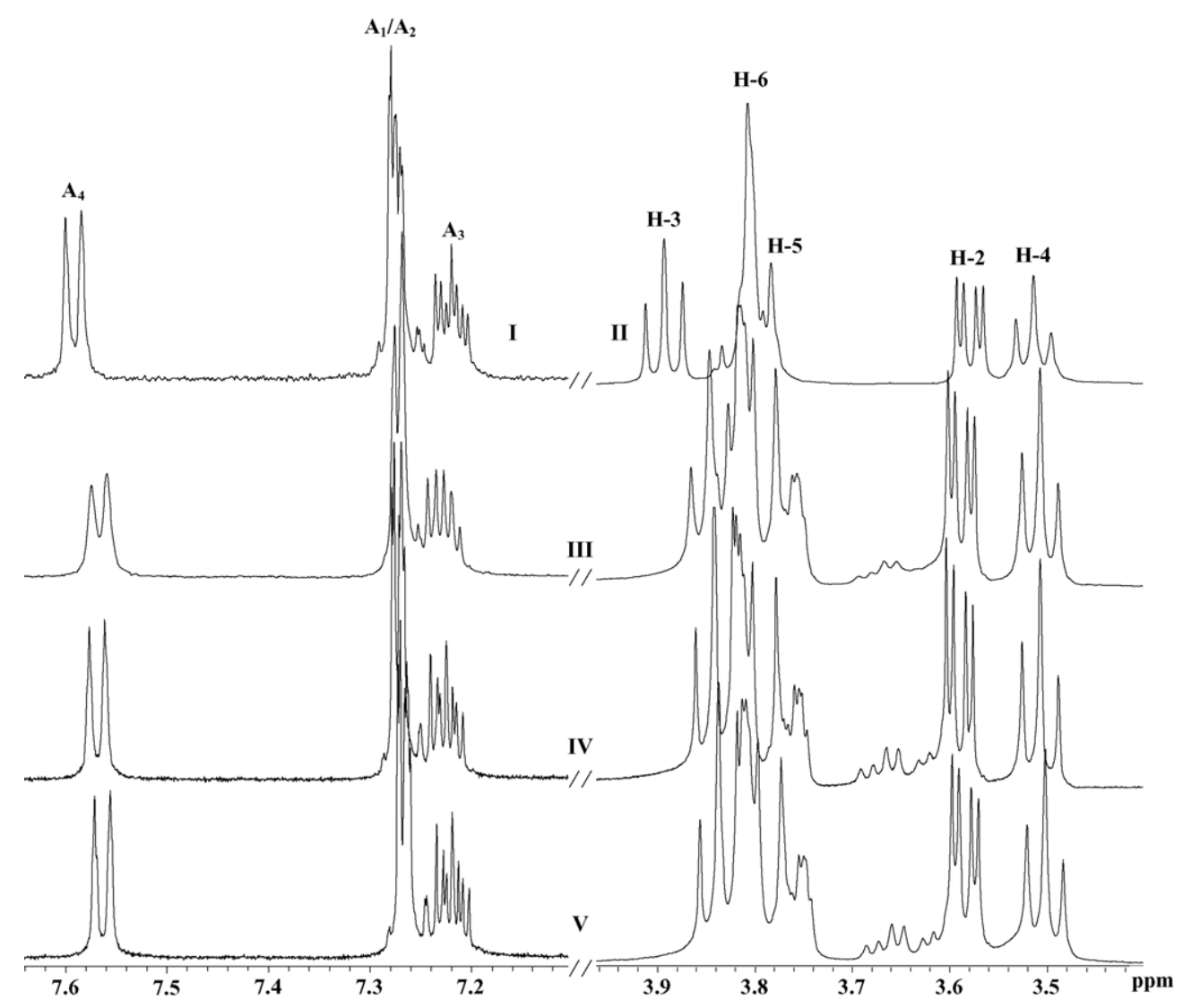

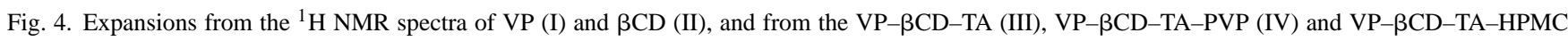
(V) complexes. 
exterior protons of $\beta C D$ were more or less influenced, we cannot exclude the existence of interactions with external surface of the macrocycle that could be ascribed to hydrogen bond formation with the hydroxyl groups at the edge of the $\mathrm{CD}$ cavity with the guest molecule and the co-complexing agents, namely TA and polymers.

Protons of VP were assigned by analysis of onedimensional ${ }^{1} \mathrm{H}$ NMR spectra and two-dimensional chemical shift correlation spectra (COSY). In this process, the assignment of all individual aromatic protons of VP became difficult due to the superposition of the signals of $\mathrm{H}-\mathrm{A}_{1}$ and $\mathrm{H}-\mathrm{A}_{2}$. Table 3 summarizes all proton chemical shifts of VP in the free and complexed forms.

Changes in the chemical shifts of the guest (VP) were also monitored. The aromatic protons of the VP $(\delta: 7.1-7.6)$, $\mathrm{H}-\mathrm{A}_{1} / \mathrm{A}_{2}$ and $\mathrm{H}-\mathrm{A}_{4}(-0.004$ to -0.024$)$, were shifted upfield and the $\mathrm{H}-\mathrm{A}_{3}$ proton was shifted downfield, with the exception on VP- $\beta C D-T A-P V P$, where all the aromatic protons were shifted upfield. The extent of the displacements depended on the system studied, with a general tendency for higher $\Delta \delta$ in the multicomponent complexes with PVP. The upfield shifts indicate that these protons are close to a host atom which is rich in $\pi$-electrons, in this case associated with oxygen atoms, and also reflects conformational changes produced by inclusion. On the other hand, the downfield shift observed is probably due changes in local polarity or to deshielding effects caused by van der Waals interactions between the drug and carbohydrate chains (Djedaini et al., 1990; Ganza-Gonzalez et al., 1994; Uccello-Barretta et al., 1993). These findings suggest that the aromatic moiety of VP is located inside the CD cavity. Moreover, the proton signal corresponding to TA showed an appreciable upfield shift indicative of its involvement in interactions with the $\beta C D$ and VP molecules and, therefore, a possible role in multicomponent complex formation. From ${ }^{1} \mathrm{H}$ NMR data, we can assume that TA is strictly involved in the molecular assembly. In particular, TA seems to be strictly implicated in the complexation process, by establishing electrostatic interactions with protonated atoms of VP that results in the formation of an ion-pair, and by the formation of hydrogen bonds with the hydroxy groups of $\beta C D$. These results are in agreement with previously reported ${ }^{1} \mathrm{H}$ NMR studies for multicomponent complexes (Faucci et al., 2000; Fenyvesi et al., 1999; Selva et al., 1998). Additionally we did also observe a general tendency for higher chemical shift displacements of the protons of both VP and $\beta C D$ molecules in the multicomponent complexes with PVP and HPMC. This effect may be credited to the ability of polymers in establishing different interactions (hydrophobic bonds, van der Waals dispersion forces or hydrogen bonds) with the outer surface of the $\mathrm{CD}$ molecules and with drug-CD complexes forming drug-CD-polymer aggregates (Hládon and Cwiternia, 1994; Valero et al., 2003) and consequently reflected the important role in the stabilization of VP-CD-TA multicomponent complexes.

The continuous variation method was then adopted to verify the stoichiometry of VP- $\beta C D-T A$ complexes. The

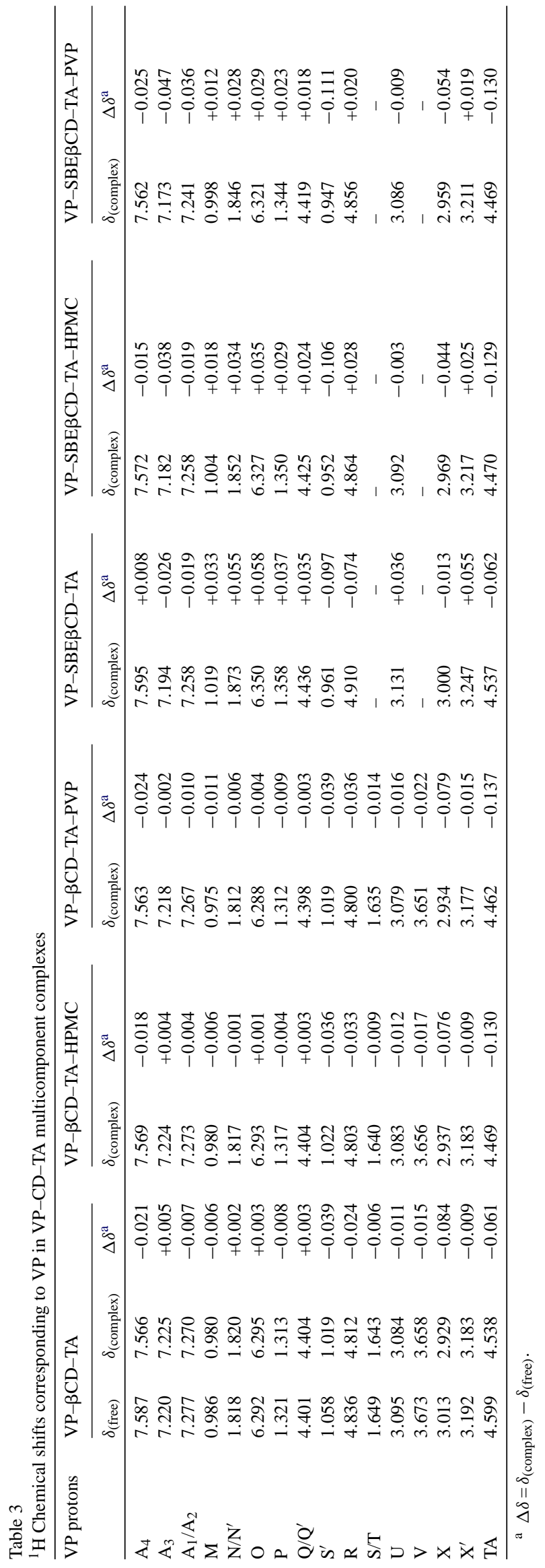



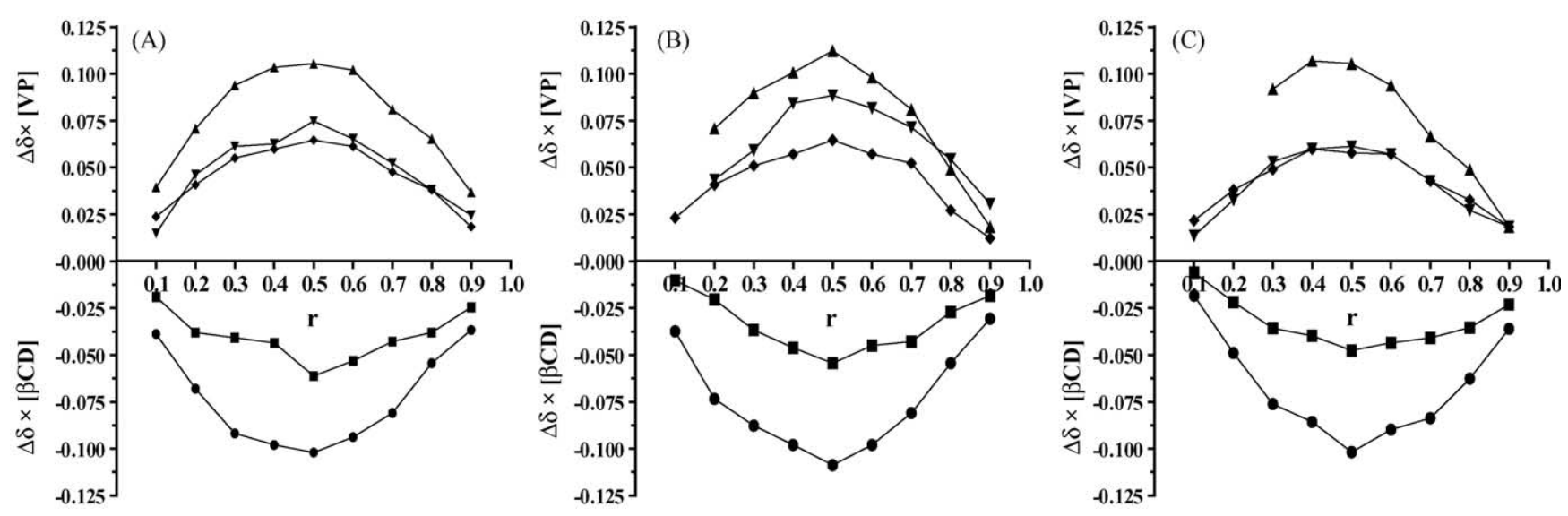

Fig. 5. Continuous variation plots for VP and $\beta C D$ protons in VP- $\beta C D-T A(A)$, VP- $\beta C D-T A-P V P(B)$ and VP- $\beta C D-T A-H P M C ~(C)$ multicomponent complexes [protons of VP: $(\boldsymbol{\Lambda}) \mathrm{N} / \mathrm{N}^{\prime},(\boldsymbol{\nabla}) \mathrm{O}$ and $(\bullet) \mathrm{U}$; protons of $\beta \mathrm{CD}$ : $(\boldsymbol{\square}) \mathrm{H}-3$ and $(\boldsymbol{\bullet}) \mathrm{H}-5$ ].

${ }^{1} \mathrm{H}$ chemical shift $(\delta)$ was measured at different ratios of drug/CD, while keeping the total $[\mathrm{VP}]+[\mathrm{CD}]$ constant. The calculated quantities $\Delta \delta \times[\mathrm{VP}]$ (or $\Delta \delta \times[\mathrm{CD}]$ ) were proportional to the concentration of the inclusion complex and could thus be plotted against " $r$ ". The continuous variation plots (Fig. 5) for some of the most markedly affected protons of VP and $\beta C D$ confirmed the $1: 1(\mathrm{VP}-\beta C D)$ stoichiometry, since the maximum was at $r=0.5$. These results are in complete accordance with the above reported phase-solubility studies.

\subsection{2. $V P-S B E \beta C D-T A$ multicomponent complexes}

The complexity of the ${ }^{1} \mathrm{H}$ NMR spectra of SBE $\beta C D$ prevents an accurate detection of the shifts induced by the complexation process. Actually, the ${ }^{1} \mathrm{H}$ NMR spectra of this $\mathrm{CD}$ are relatively uninformative, since there is an extensive overlapping of all protons between $\delta 3.5$ and 4.1 (Luna et al., 1997). For this reason, the information about the existence of an interaction in solution was solely derived from the observation VP proton shifts in VP-SBEßCD-TA complexes (Fig. 6). In these complexes, we observed a pronounced chemical shift displacement for the aromatic protons of VP $(-0.019$ to -0.0047$)$. In the VP-SBE $\beta C D-T A$ complex, the $\mathrm{H}-\mathrm{A}_{1} / \mathrm{H}-\mathrm{A}_{2}$ and $\mathrm{H}-\mathrm{A}_{3}$ protons experienced upfield shifts that were inferred to the shielding effect of the hydrophobic cavity of SBE $\beta C D$, while a downfield shift was observed for the $\mathrm{H}$ $\mathrm{A}_{4}$ proton. In contrast, all aromatic protons of VP were shifted upfield in VP-SBEßCD-TA-polymer multicomponent complexes. This slight variation may reflect some differences in the structures of these complexes. Hence, the downfield displacement of $\mathrm{H}-\mathrm{A}_{4}$ proton showed by the VP-SBE $\beta C D-T A$ complex was attributed to a structure rearrangement of VP molecule upon complexation (Veiga et al., 2001) and the upfield shift for the resonances of the aromatic protons indicates that the aromatic portion of VP is mainly involved in the complex formation with SBEßCD (Oh et al., 1998). Another disparity observed between VP-SBEßCD-TA multicomponent complexes respects the magnitude of the chemical shift displacements, since in general higher values were reported

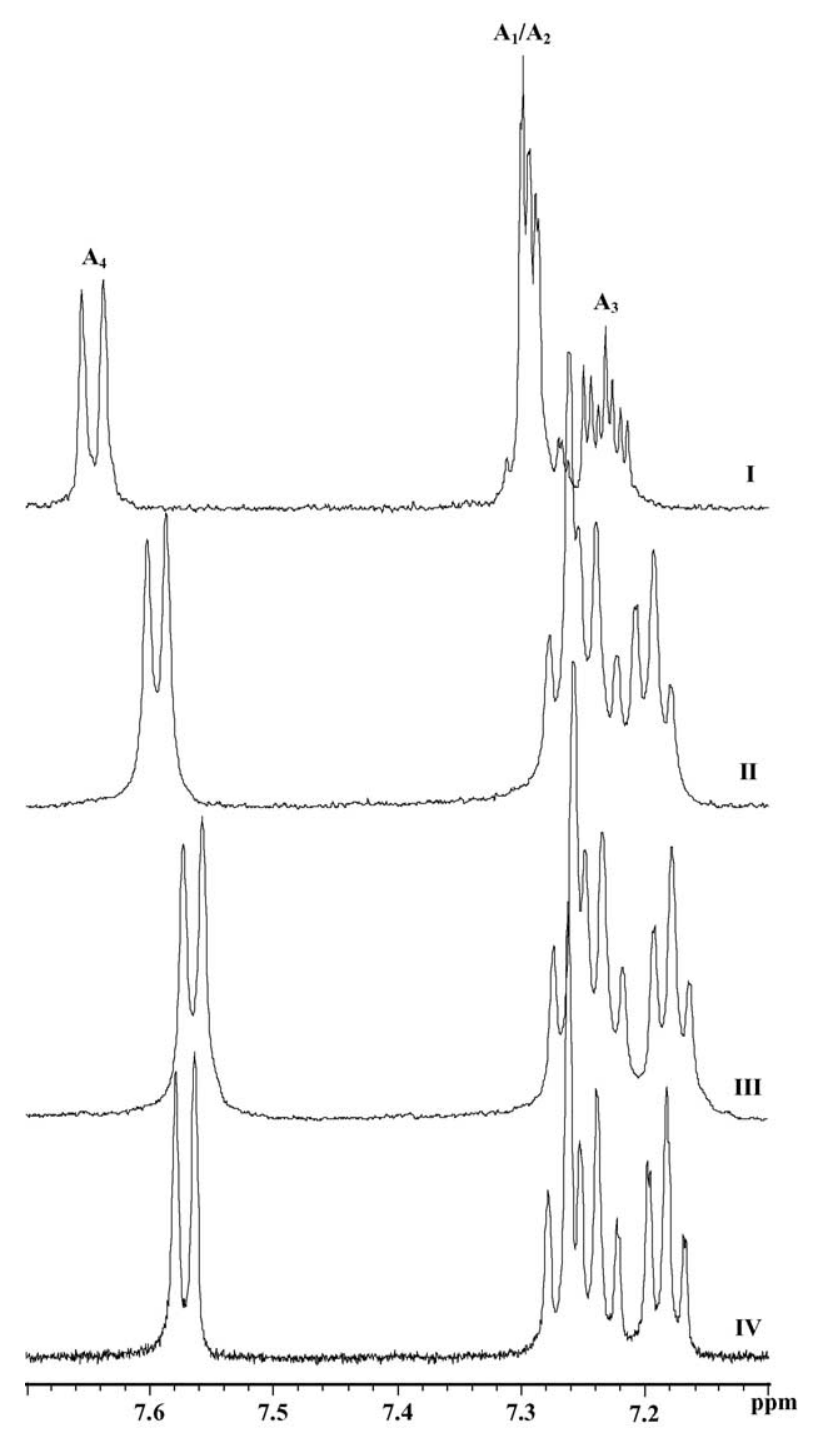

Fig. 6. Expansions from the ${ }^{1} \mathrm{H}$ NMR spectra of VP (I) and VP-SBE $\beta C D-$ TA (II), VP-SBEßCD-TA-PVP (III) and VP-SBEßCD-TA-HPMC (IV) multicomponent complexes. 
for the VP-SBEßCD-TA-polymer complexes. Taking into account that the extent of these displacements is dependent on the relative strength of the interactions between these aromatic protons and the hydrogen atoms of the $\beta C D$ cavity, we can assume that a deeper insertion of the aromatic moiety of VP was produced by the presence of the polymers. These observations are in total agreement with the reported results of the phase-solubility studies, since higher $K_{\mathrm{C}}$ values were obtained for VP-SBE $\beta C D-T A-$ polymer complexes than for the VP-SBEßCD-TA complex.

In what concerns guest resonances, although there is a general tendency for chemical shift displacements, upfield for the aromatic protons and downfield for the other ones, there is no simple explanation in terms of inclusion or non-inclusion. The chemical shift displacement of VP protons must be regarded as a result of a combination of interactions with the macrocycle and time-averaged conformational changes of the included molecules (Redondo et al., 1999). Nevertheless, the downfield shift of the resonances of the alkyl protons was ascribed to the interaction with the hydrophilic external part of the CD molecule (Uccello-Barretta et al., 1993) and to conformational changes produced by the inclusion (Redenti et al., 1999).

The same feature, as in VP- $\beta C D-T A$ multicomponent complexes, was observed with the protons of TA, that is, an upfield shift related to the co-complexing performance of the $\alpha$-hydroxy-acid. Larger chemical shift displacements were also observed for the VP protons in the multicomponent complexes with both HPMC and PVP polymers, which might reveal a tight association between VP, SBEßCD and TA in their presence. The magnitudes of the shift displacements of VP protons were greater in SBE $\beta C D$ than in $\beta C D$ complexes. This may indicate that the aromatic moiety of VP is included deeper into the expanded hydrophobic cavity of SBE $\beta C D$, since the sulbobutylation of the hydroxyl groups may change the nature of host-guest interaction and could therefore expand the hydrophobic region of the CD cavity, enhancing the binding of the guest. More- over, the anionic SBE $\beta C D$ produces a downfield shift displacement of almost all non-aromatic protons, oppositely to the $\beta C D$ that induced preponderantly upfield displacement in these hydrogen atoms. This fact prompts for a different mode of interaction between VP and both CDs (Owens et al., 1997) and may also reflect a distinct chemical microenvironment.

Considering all results mentioned above, we can presume the existence of important structural differences in VP- $\beta C D-T A$ and VP-SBE $\beta C D-T A$ multicomponent complexes since SBE $\beta C D$ has an average of seven negative charges and therefore the most favourable position of positively amino charged groups of VP must be not far away from the negatively moieties of the $\mathrm{CD}$. The drug molecule has to arrange itself within the hydrophobic cavity to allow for the electrostatic interactions with the charged substituents, and, at the same time, the protonated nitrogen atoms of the drug will interact with TA molecules resulting in the creation of an ion-pair, without the formation of chemical bonds (Másson et al., 1998). In summary, SBEßCD most likely encloses the aromatic ring of VP due to hydrophobic interaction and the resulting complex is synergistically stabilized by additional electrostatic interaction between sulfobutyl moieties of the host and the protonated nitrogen atoms of the guest and by hydrogen bond forming with the 2- and 3-hydroxy groups of the $\mathrm{CD}$ and the resulting ion-pair.

The continuous variation method was subsequently applied to all protons of the VP molecule in VP-SBEßCD-TA complexes for confirming the stoichiometry of the complexes, yielding identical results. In all cases, Job's plots (Fig. 7) showed a maximum at $r=0.5$, indicating the formation of a complex where the complexing agent (SBEßCD) is present in first-order degree with respect to the drug, within the range of the investigated concentrations. The 1:1 stoichiometry obtained is also strongly supported by the nature of the SBE $\beta C D$ molecule, given that each SBE $\beta C D$ molecule carries an average of seven negative charges that make formation of higher-order complexes difficult (Loftsson et al.,
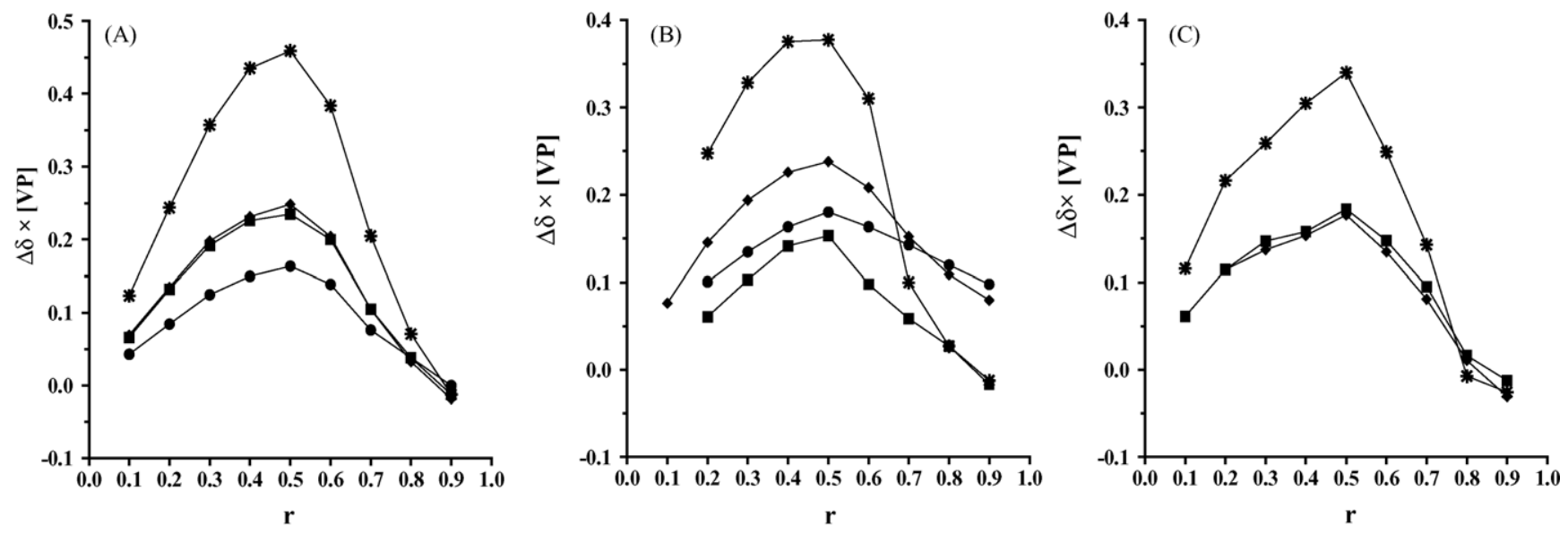

Fig. 7. Continuous variation plots for VP protons in VP-SBEßCD-TA (A), VP-SBEßCD-TA-PVP (B) and VP-SBEßCD-TA-HPMC (C) multicomponent complexes [protons of VP: (*) N/N' $(\bullet) \mathrm{O},(\boldsymbol{\square}) \mathrm{Q} / \mathrm{Q}^{\prime}$ and $(\bullet) \mathrm{R}$ ]. 
2002). These results are once again in agreement with the above related phase-solubility studies.

\subsection{ROESY studies}

Deeper insight about the geometry of VP-CD-TA multicomponent complexes can be derived from the evidences of spatial proximities between protons of host and guest molecules. In the case of inclusion complex formation, the drug molecule penetrates the cavity of CD and dipole-dipole interactions can be detected between the glucose $\mathrm{H}-3$ and $\mathrm{H}-5$ protons inside the $\mathrm{CD}$ cavity and protons of the guest. This can be achieved by ${ }^{1} \mathrm{H}-{ }^{1} \mathrm{H}$ nuclear Overhauser NMR experiments. Unfortunately, the inherently small nuclear Overhauser effect (NOE) values, due to unfavourable correlation times of CD complexes in water solution, clearly constitute a drawback in studying the mutual geometric relationships of this kind of structure. This problem is normally overcome by collecting NOEs in the rotating frame (ROEs), as with this technique the effects are always positive (Amato et al., 1998; Forgo and D'Souza, 1998). In two-dimensional rotating frame Overhauser (ROESY) experiments, dipolar interactions between protons at a distance less than 3-4 $\AA$ are detected as cross-peaks in a bi-dimensional map, indicating the reality of the inclusion and the portion of the guest situated in the torus cavity (Schneider et al., 1998). Thus, ROESY experiments were used with the purpose of providing useful information in the elucidation of the supramolecular system structures present in solution, namely the average extent of penetration and the direction of inclusion of VP in the host cavity.

\subsubsection{VP- $\beta C D-T A$ multicomponent complexes}

Inspection of the ROESY maps relative to VP- $\beta C D-T A$ multicomponent complexes allows us to establish a spatial proximity between the aromatic hydrogens of VP and the inner protons of $\beta C D$. An expansion of the ROESY spectrum illustrating ROEs of VP aromatic protons in the VP- $\beta C D-T A$ complex is reported in Fig. 8. The spectrum shows the existence of evident intermolecular cross-peaks between the interior $\beta C D$ hydrogens with all VP hydrogens of the aromatic ring, that is, $\mathrm{H}-\mathrm{A}_{3}, \mathrm{H}-\mathrm{A}_{1} / \mathrm{A}_{2}$ and $\mathrm{H}-\mathrm{A}_{4}$ resonating at $\delta$ 7.218-7.225, 7.267-7.277 and 7.563-7.587, respectively. These correlations were of different intensities being the order of the magnitude as follow: $\left[\mathrm{H}-\mathrm{A}_{1} / \mathrm{A}_{2} \leftrightarrow \mathrm{H}-3\right]>[\mathrm{H}-$ $\left.\mathrm{A}_{3} \leftrightarrow \mathrm{H}-3\right] \approx\left[\mathrm{H}-\mathrm{A}_{4} \leftrightarrow \mathrm{H}-3\right]>\left[\mathrm{H}-\mathrm{A}_{4} \leftrightarrow \mathrm{H}-5\right]$. Since higher strength dipolar correlations were observed between all VP aromatic protons and the $\mathrm{H}-3$ proton of $\beta C D$ than the ones observed between the $\mathrm{H}-\mathrm{A}_{4}$ proton of $\mathrm{VP}$ and the $\mathrm{H}-5$ proton of $\beta C D$, we could definitively suggest an internalization of the VP moiety into the $\beta C D$ hydrophobic cavity, being this inclusion preferentially made from the wider rim of $\beta C D$ truncated cone. Moreover, the inexistence of intermolecular cross-peaks between TA protons and the inner protons of the host molecule exclude the inclusion of the hydroxy-acid within $\beta C D$ cavity.

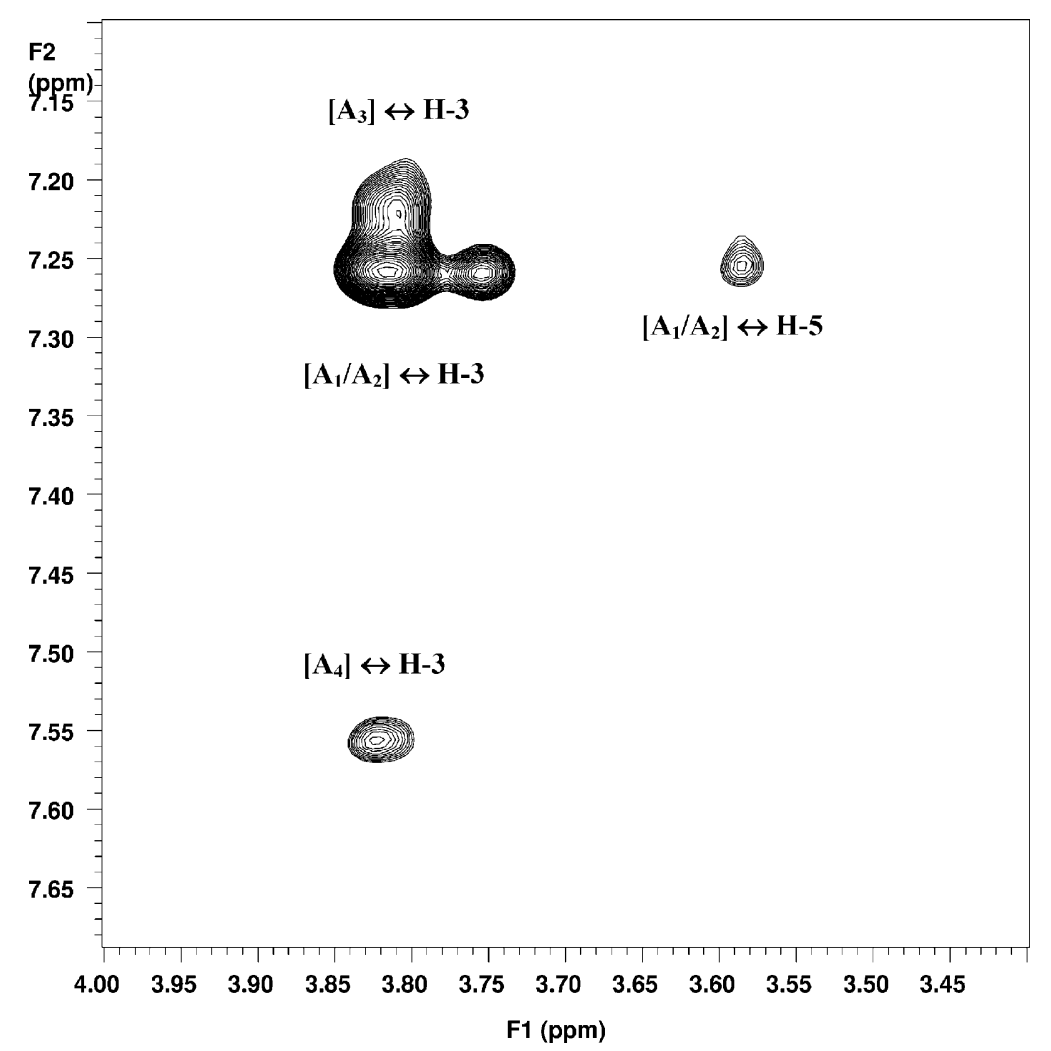

Fig. 8. Expansion from the ROESY spectrum of VP- $\beta C D-T A$ multicomponent complex. 
The VP- $\beta C D-T A-p o l y m e r$ ROESY spectra demonstrated comparable results, with equivalent dipolar interactions evidenced between the inner protons of $\beta C D$ and the aromatic protons of VP, which indicates that a similar inclusion process of the aromatic VP moiety must occur in these systems. However, the intensities of the cross-peaks were greater in the presence of the polymers (PVP and HPMC), corroborating the previous results reported here, i.e., a somehow superior stabilization of the resultant supramolecular assembly by interaction with the outer surface of the inclusion complex.

From NMR data, there are clear evidences that the more or less planar VP is tilted inside the $\beta C D$ cavity and this arrangement allows the guest molecule to occupy most of the available cavity space, while keeping the polar susbstituents close to the hydroxy groups of the $\beta C D$ rim. The polar substituents, namely the basic nitrogen atoms, may then protrude to the exterior environment and are stabilized by tartarate ions and by the hydroxy groups of the CD rim.

\subsubsection{VP-SBEßCD-TA multicomponent complexes}

In the two-dimensional ROESY spectra of VP-SBEßCD-TA multicomponent complexes, crosspeaks connecting two proton resonances were unambiguously observed between the internal protons of the $\beta C D$ derivative and the aromatic protons of VP. Fig. 9 shows a contour plot of a section of the ROESY spectrum of VP-SBEßCD-TA-HPMC complex $(\delta: 1.60-4.0)$. Very intense ROE interactions were observed between $\mathrm{H}-\mathrm{A}_{3}$, $\mathrm{H}-\mathrm{A}_{1} / \mathrm{A}_{2}$ and $\mathrm{H}-\mathrm{A}_{4}$ aromatic protons of $\mathrm{VP}$, and both internal protons of SBE $\beta C D$ (in the 3.4-3.9 ppm region) for all three VP-SBEßCD-TA complexes under study, indicating also in these systems the involvement of VP aromatic moiety in the complexation. We also detected feeble intermolecular cross-peaks between the aromatic protons in VP, and the b- $\mathrm{CH}_{2}$ and $\mathrm{c}-\mathrm{CH}_{2}$ hydrogens of the sulfobutyl side chains of SBEßCD in the $\delta 2.85-2.75$ and 1.60-1.75 regions, but those were just observable in multicomponent containing polymers. Using these NMR results, it is reasonable to ascribe these effects to the formation of an inclusion complex between SBEBCD and VP, through the inclusion of the aromatic moiety of VP. As previously reported for VP- $\beta C D-T A$ multicomponent complexes, the presence of polymers enhanced even more the magnitude of all observed dipolar interactions making it possible to visualize the interaction between VP and the alkyl side chains of the CD derivative.

The greater ROE intensities observed in VP-SBEßCD-TA multicomponent complexes relative to the corresponding complexes with $\beta C D$ again suggested that VP was embedded in a more hydrophobic environment in the former inclusion complexes; hence, SBEßCD exhibited the strongest inclusion property. This is due to attractive electrostatic interactions, since SBEBCD is negatively charged while VP is positively charged under the experimental conditions. As previously reported by Zia et al.

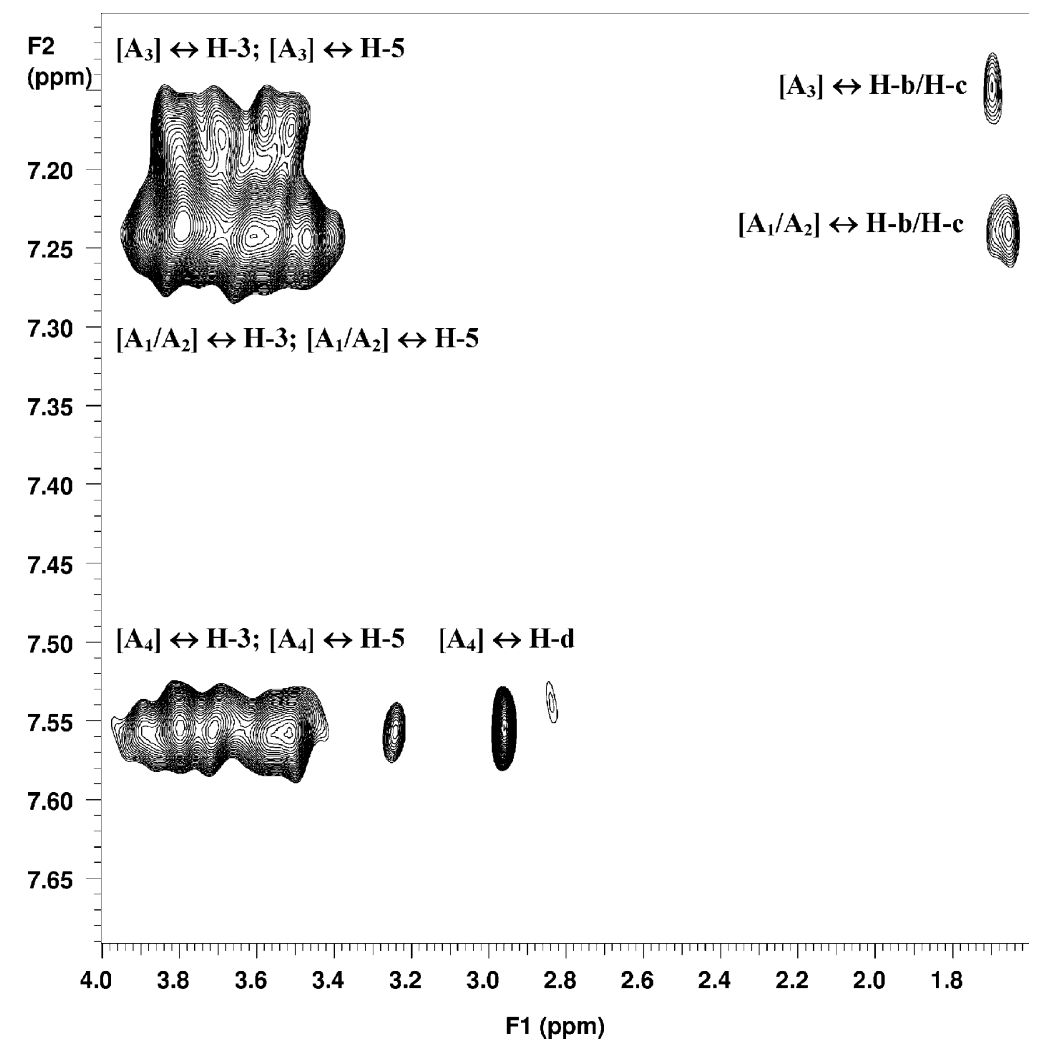

Fig. 9. Expansion from the ROESY spectrum of VP-SBEßCD-TA-PVP multicomponent complex. 
(2001), chemical modifications of $\beta C D$ with sulfobutylether substituents may provide supplementary binding sites for molecules capable of forming ionic interactions with the charged sulfonate moieties. The charged sulfonate groups of each CD are likely to repel one another by extending out and away from each other providing a hydrophobic region near the cavity composed of only alkyl ether protons of the sulfobutyl groups. Thus, the alkyl chains of sulfobutyl moieties may provide additional hydrophobic regions for stabilization of the complex, potentially counterbalancing the negative effects of steric interference. Sulfobutyl alkyl chains may also provide an extension of the $\mathrm{CD}$ cavity with which the guest molecule may interact. Consequently, the expansion of the hydrophobic CD cavity enhances the possibility of VP binding by means of a hydrophobic effect and, in addition, complexation with VP seems to occur not only via the $\mathrm{CD}$ cavity, but also via the alkyl chains near the cavity.

The acidic character conferred by TA allows the positively charged form of VP to be predominant in the complexation media. The experimental results show that the aromatic moiety of VP is deeply included into the hydrophobic cavity of the SBE $\beta C D$. Furthermore, we can assume that TA is kept in the proximity of the external rim of SBE $\beta C D$ by a concerted mechanism that involves the binding of the hydrophobic part of the drug and simultaneous formation of an ion-pair that is accommodated near the CD cavity. In addition, TA participates actively in the complex formation by interacting with the external hydrogen bond system of CDs (Redenti et al., 2000) as proved by the significant chemical shift displacements of TA protons in VP complexes. At the same time, it seems that the naphthyridine protonated nitrogen atom of VP is synergistically stabilized by additional electrostatic interaction with the charged head group of sulfobutyl moieties of the host.

Despite the uncertainty on the role of PVP and HPMC in stabilizing the resultant multicomponent complex, due to a very broad and undefined NMR spectra, we can presume from all reported NMR data that the derived VP-CD-TA-polymer complexes must be additionally stabilized by outside contributions in a similar way as with micelles, forming VP-CD-TA-polymer aggregates or a co-complex, i.e., a complex between several VP-CD-TA molecules and a polymer chain [(VP-CD-TA $)_{n}$-polymer] (Ribeiro et al., 2003b).

\section{Conclusions}

The present results suggest that the increases in VP solubility resulted from a synergistic effect in presence of CDs, TA and polymers, as well as from an increase on CD complexation efficiency. Despite the decrease in the affinity of VP to the hydrophobic CD cavity in the presence of TA and hence lower $K_{\mathrm{C}}$ values obtained in VP-CD-TA multicomponent complexes relatively to VP-CD complexes, the achieved sol- ubility was drastically improved. Given that the complexation efficiency is defined by $K_{\mathrm{C}} \times S_{0}$ (Loftsson et al., 1999), the decrease in $K_{\mathrm{C}}$ values observed for the multicomponent complexes was significantly overcome by the increase in $S_{0}$ in the presence of the hydroxy-acid. Additionally, the polymers had a positive effect on the $K_{\mathrm{C}}$ values of VP-CD-TA-polymer multicomponent complexes emphasizing even more VP solubility and the complexation efficiency.

The stoichiometry of the multicomponent complexes provided by the phase-solubility diagrams was further confirmed by the continuous variation method which indicated a 1:1 stoichiometry and the formation of complexes where the complexing agents (CDs) were present in first-order degree with respect to VP.

Finally, high resolution ${ }^{1} \mathrm{H}$ NMR techniques made it possible to identify atomic interactions between the guest and host and to establish geometrical relationships. The hallmarks of the inclusion within CD cavities (chemical shift displacements of the H-3 and H-5 protons of CDs and protons of VP molecule, and intermolecular ROESY correlations between aromatic guest protons and the inner protons of CDs) were clearly demonstrated. Moreover, the changes on the ${ }^{1} \mathrm{H}$ signals measured in the presence of $\beta C D$ were of lower magnitude than those induced by SBE $\beta C D$, and the greater magnitude of ROEs in VP-SBEßCD-TA multicomponent complexes indicated a stronger interaction of VP with the latter $C D$, suggesting that VP is embedded in a more hydrophobic environment in the inclusion complexes with SBE $\beta C D$. These observations are consistent with the insertion of the aromatic moiety of VP molecule into the CD cavity from the wider rim of the truncated cone of the $\mathrm{CD}$, being deeply inserted in SBE $\beta C D$ multicomponent complexes and less included in $\beta C D$ complexes. We believe that the pyridine protonated nitrogen of VP molecule forms an ionpair with TA, as stated by the important improvement in VP solubility in these systems and by the significant chemical shift displacements of TA protons in VP complexes. This ion-pair seems to participate actively in the complex formation by interacting with the external hydroxy groups of $\mathrm{CD}$ secondary rim. In addition, the naphthyridine protonated nitrogen atom of VP is synergistically stabilized by an electrostatic interaction with the charged head group of sulfobutyl moieties of the SBE $\beta C D$, resulting in the enhanced stability of VP-SBE $\beta C D-T A$ complexes relatively with the $\beta C D$ ones.

The higher $K_{\mathrm{C}}$ values obtained from the solubility studies along with the greater chemical shift differences and ROE dipolar correlations in VP-CD-TA-polymer complexes support the involvement of polymers in the complexation process. Accordingly, we presume that the conformation of the polymer chains play an important role in the exterior stabilization of the above mentioned multicomponent complexes by forming co-complexes between several VP-CD-TA molecules and a polymer chain [(VP-CD-TA $)_{n}$-polymer] that involve relatively weak forces such as van der Waals interactions and hydrogen bonds. 


\section{References}

Amato, M.E., Likowitz, K.B., Lombardo, G.M., Pappalardo, G.C., 1998. Hight-field NMR spectroscopic techniques combined with molecular dynamics simulations for the study of the inclusion complexes of $\alpha$ - and $\beta$-cyclodextrin with the cognition activator 3-phenoxypiridine sulphate (Cl-844). Magn. Reson. Chem. 36, 693-705.

Chiesi, P., Ventura, P., Pasini, M., Szejtli, J., Vikmon, M., Redenti, E. 1999. Highly soluble multicomponent inclusion complexes containing a base type drug, an acid and a cyclodextrin. USP 5,855,916.

Djedaini, F., Lin, S.-Z., Perly, B., Wouessidjewe, D., 1990. High-field nuclear magnetic resonance techniques for the investigation of a $\beta$-cyclodextrin:indomethacin inclusion complex. J. Pharm. Sci. 79, 643-646.

Djedaini, F., Perly, B., 1991. Nuclear magnetic resonance of the stoichiometries in $\beta$-cyclodextrin:steroid inclusion complexes. J Pharm. Sci. 80, 1157-1161.

Faucci, M.T., Melani, F., Mura, P., 2000. ${ }^{1} \mathrm{H}$ NMR and molecular modelling techniques for the investigation of the inclusion complex of econazole with $\alpha$-cyclodextrin in the presence of malic acid. J. Pharm. Biomed. Anal. 23, 25-31.

Fenyvesi, E., Vikmon, M., Szeman, J., Redenti, E., Delcanale, M., Ventura, P., Szejtli, J., 1999. Interaction of hydroxy-acids with $\beta$ cyclodextrin. J. Incl. Phenom. Macroc. Chem. 33, 339-344.

Fernandes, C.M., Carvalho, R.A., Pereira da Costa, S., Veiga, F.J., 2003. Multimodal encapsulation of nicardipine hydrochoride by $\beta$-cyclodextrin, hydroxypopyl- $\beta$-cyclodextrin and triacetyl- $\beta$ cyclodextrin in solution. Structural studies by ${ }^{1} \mathrm{H}$ NMR and ROESY experiments. Eur. J. Pharm. Sci. 18, 285-296.

Forgo, P., D’Souza, V.T., 1998. The application of selective ROE experiments to study solution structures of cyclomaltooligosacharide derivatives and complexes. Carbohydr. Res. 306, 473-478.

Ganza-Gonzalez, A., Vila-Jato, J.L., Anguiano-Igea, S., Otero-Espinar, F.J., Blanco-Méndez, J., 1994. A proton nuclear magnetic resonance study of the inclusion complex of naproxen with $\beta$-cyclodextrin. Int. J. Pharm. 106, 179-185.

Higuchi, T., Connors, K., 1965. Phase-solubility techniques. Adv. Anal. Chem. Instr. 4, 117-210.

Hládon, T., Cwiternia, B., 1994. Physical and chemical interactions between cellulose ethers and $\beta$-cyclodextrins. Pharmazie 49, 497-500.

Loftsson, T., Magnusdóttir, A., Masson, M., Sigurjonsdóttir, J., 2002. Self-association and cyclodextrin solubilization of drugs. J. Pharm. Sci. 91, 2307-2316.

Loftsson, T., Másson, M., Sirgurjónsdóttir, J.F., 1999. Methods to enhance the complexation efficiency of cyclodextrins. S.T.P Pharma Sci. 9, 237-242.

Luna, E.A., Velde, D.G.V., Tait, R.J., Thompson, O.D., Rajewski, R.A., Stella, V.J., 1997. Isolation and characterization by NMR spectroscopy of three monosubstitued 4-sulfobutyl ether derivatives of cyclomaltoheptaose ( $\beta$-cyclodextrin). Carbohydr. Res. 299, 111-118.

Másson, M., Loftsson, T., Jonsdóttir, S., Friðriksdóttir, H., Petersen, D.S., 1998. Stabilization of ionic drugs through complexation with nonionic and ionic-cyclodextrins. Int. J. Pharm. 164, 45-55.

Mitra, S., Das, R., Mukherjee, S., 1998. Intramolecular proton transfer in inclusion complexes of cyclodextrins; Role of water and highly polar non-aqueous media. J. Phys. Chem. B 102, 3730-3735.

Mura, P., Faucci, M.T., Manderioli, A., Bramanti, G., 2001. Multicomponent systems of econazole with hydroxyacids and cyclodextrins. J. Incl. Phenom. Macroc. Chem. 39, 131-138.
Oh, I., Lee, M.-Y., Lee, Y.-B., Shin, S.-C., Park, I., 1998. Spectroscopic characterization of ibuprofen/2-hydroxypropyl- $\beta$-cyclodextrin. Int. J. Pharm. 175, 215-223.

Owens, P.K., Fell, A.F., Coleman, M.W., Kinns, M., Berridge, J.C., 1997. Use of ${ }^{1} \mathrm{H}$ NMR spectroscopy to determine the enantioselective mechanism of neutral and anionic cyclodextrins in capillary electrophoresis. J. Pharm. Biomed. Anal. 15, 1603-1619.

Redenti, E., Szente, L., Szejtli, J., 2000. Drug/cyclodextrin/hydroxy acid multicomponent systems. Properties and pharmaceutical applications. J. Pharm. Sci. 89, 1-8.

Redenti, E., Ventura, P., Fronza, G., Selva, A., Rivara, S., Plazzi, V.P., Mor, M., 1999. Experimental and theorical analysis of the interaction of $(+/-)$-cis-ketoconazole with $\beta$-cyclodextrin in the presence of $(+)$ L-tartaric acid. J. Pharm. Sci. 88, 599-607.

Redondo, J., Blasquez, M.A., Torrens, A., 1999. Chiral discrimination of the analgesic cizolirtine by using cyclodextrins: a ${ }^{1} \mathrm{H}$ NMR on the solution stuctures of their host-guest complexes. Chirality 11, 694-700.

Ribeiro, L., Ferreira, D., Veiga, F., 2003a. Physicochemical investigation of the effects of water-soluble polymers on vinpocetine complexation with $\beta$-cyclodextrin and its sulfobutyl ether derivative in solution and solid state. Eur. J. Pharm. Sci. 20, 253-266.

Ribeiro, L., Loftsson, T., Ferreira, D., Veiga, F., 2003b. Investigation and physicochemical characterization of vinpocetine-sulfobutyl ether $\beta$ cyclodextrin binary and ternary complexes. Chem. Pharm. Bull. 51, 914-922.

Saenger, W., 1980. Cyclodextrin inclusion compounds in research and industry. Angew. Chem. Int. Ed. Eng. 19, 344-362.

Schneider, H.-J., Hacket, F., Rudiger, V., 1998. NMR studies of cyclodextrins and cyclodextrin complexes. Chem. Rev. 98, 17551785.

Selva, A., Redenti, E., Ventura, P., Zanol, M.C.B., 1998. Study of $\beta$ cyclodextrin-ketoconazole-tartaric acid multicomponent non-covalent association by positive and negative ionspray mass spectrometry. J. Mass Spectrom. 33, 729-734.

Szejtli, J., 1988. Cyclodextrins. In: Szejtli, J. (Ed.), Cyclodextrin Technology. Kluwer Academic Publishers, Dordrecht, pp. 4582.

Uccello-Barretta, G., Chiavacci, C., Bertucci, C., Salvadori, P., 1993. Stereochemistry and dynamics of the inclusion complex of (S)-(+)fenoprofen with cyclomaltoheptaose ( $\beta$-cyclodextrin). Carbohydr. Res. $243,1-10$.

Uekama, K., Otagiri, M., 1987. Cyclodextrins in drug carrier systems. CRC Crit. Rev. Therap. Drug Carr. Syst. 3, 1-40.

Valero, M., Pérez-Revuelta, B.I., Rodríguez, L.J., 2003. Effect of PVP $\mathrm{K}-25$ on the formation of the naproxen: $\beta$-cyclodextrin complex. Int. J. Pharm. 253, 97-110.

Veiga, F.J.B., Fernandes, C.M., Carvalho, R.A., Geraldes, C.F.G.C., 2001. Molecular modelling studies and ${ }^{1} \mathrm{H}$ NMR: ultimate tools for the investigation of tolbutamide:hydroxypropyl- $\beta$-cyclodextrin complexes. Chem. Pharm. Bull. 49, 1251-1256.

Wilson, L.D., Verral, R.E., 1998. F and ${ }^{1} \mathrm{H}$ NMR investigation of cyclodextrin/fluorcarbon alkyl carboxylate surfactant inclusion complexes. Langmuir 14, 4710-4717.

Zia, V., Rajewski, R.A., Stella, V.J., 2001. Effect of cyclodextrin charge on complexation of neutral and charged substrates: comparison of sulfobutylether- $\beta$-cyclodextrin to hydroxypropyl- $\beta$-cyclodextrin. Pharm. Res. 18, 668-673. 